F. L. DUECKER, R. C. HEINZE, P. HERETSCH* (FREIE UNIVERSITÄT BERLIN, GERMANY) Synthesis of Swinhoeisterol A, Dankasterone A and B, and Periconiastone A by Radical Framework Reconstruction J. Am. Chem. Soc. 2020, 142, 104-108.

\section{Total Synthesis of Swinhoeisterol A, Dankasterones A and $B$, and Periconiastone $A$}

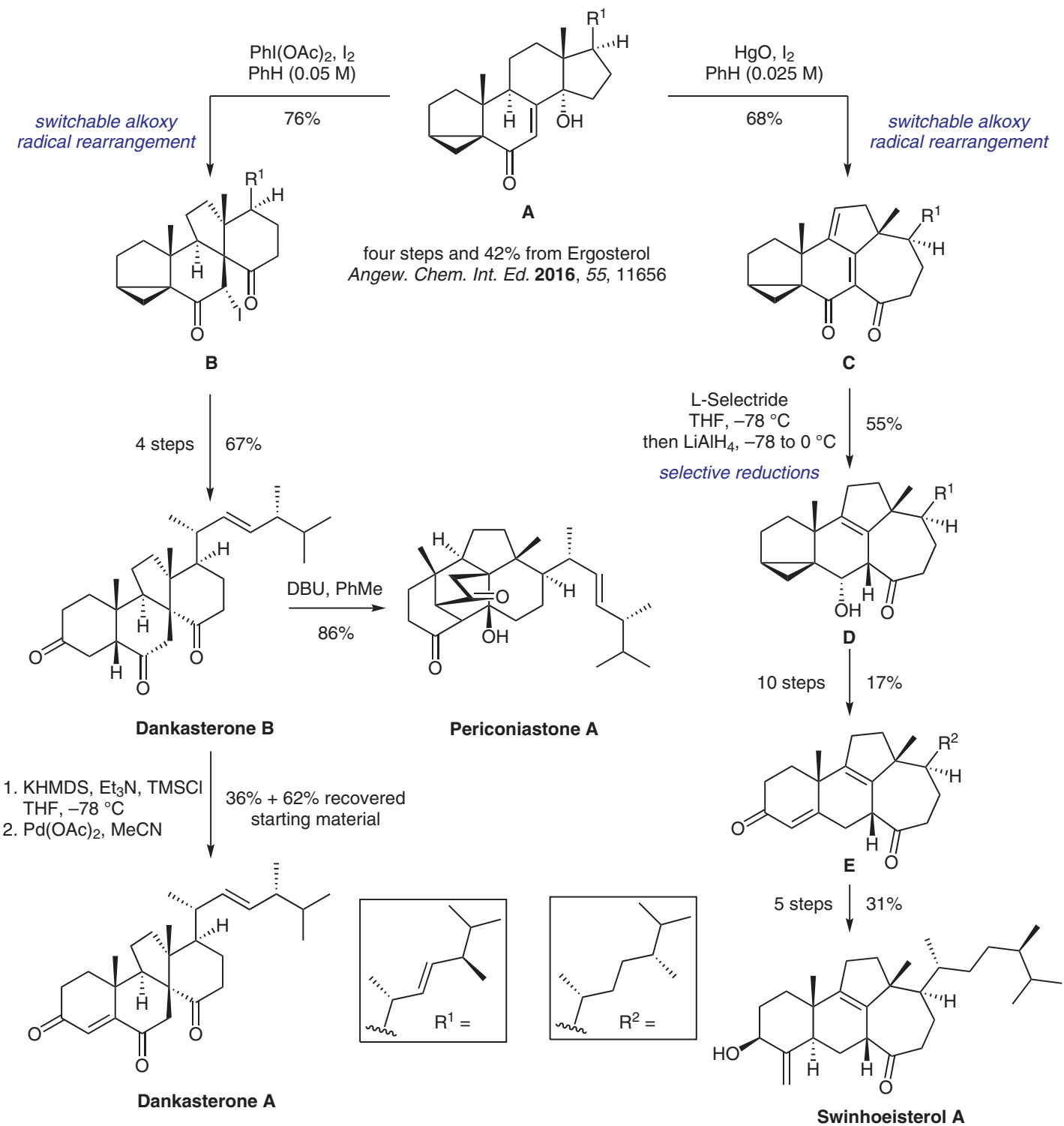

Category

Synthesis of Natural

Products and

Potential Drugs

\section{Key words}

swinhoeisterol A

dankasterone $A$

dankasterone $B$

periconiastone $A$

radical

rearrangement

skeleton

rearrangement
Significance: Heretsch and co-workers report the total synthesis of a number of structurally intriguing natural products from a common intermediate. The concise synthesis is enabled by the strategic application of a switchable alkoxy radical rearrangement.
Comment: Ergosterol is transformed by a known route to cyclopropane $\mathbf{A}$. Two different conditions were developed to lead selectively to $\mathbf{B}$ or $\mathbf{C}$. Those advanced intermediates could subsequently be converted into four different complex natural products. 